\title{
Spherical nanoindentation creep behavior of nanocrystalline and coarse- grained CoCrFeMnNi high-entropy alloys
}

\author{
Dong-Hyun Lee ${ }^{1}$, Moo-Young Seok ${ }^{1}$, Yakai Zhao ${ }^{1}$, In-Chul Choi ${ }^{2}$, Junyang $\mathrm{He}^{3}$, \\ Zhaoping $\mathrm{Lu}^{3}$, Jin-Yoo Suh ${ }^{4}$, Upadrasta Ramamurty ${ }^{5,6}$, Megumi Kawasaki ${ }^{1 *}$, \\ Terence G. Langdon ${ }^{7,8}$, Jae-il Jang ${ }^{1 *}$ \\ ${ }^{1}$ Division of Materials Science and Engineering, Hanyang University, Seoul 04763, South Korea \\ ${ }^{2}$ Institute for Applied Materials, Karlsruhe Institute of Technology, Karlsruhe 76021, Germany \\ ${ }^{3}$ State Key Laboratory for Advance Metals and Materials, University of Science and Technology Beijing, \\ Beijing 10083, People's Republic of China \\ ${ }^{4}$ High Temperature Energy Materials Research Center, Korea Institute of Science and Technology, Seoul 02792, \\ Republic of Korea \\ ${ }^{5}$ Department of Mechanical Engineering, Indian Institute of Science, Bangalore 560012, India \\ ${ }^{6}$ Center of Excellence for Advanced Materials Research, King Abdulaziz University, Jeddah 21589, Saudi \\ Arabia \\ ${ }^{7}$ Departments of Aerospace \& Mechanical Engineering and Materials Science, University of Southern California, \\ Los Angeles, CA 90089-1453, USA \\ ${ }^{8}$ Materials Research Group, Faculty of Engineering and the Environment, University of Southampton, \\ Southampton SO17 1BJ, UK
}

*Corresponding authors: jijang@ @anyang.ac.kr (J.-i. Jang), megumi@ hanyang.ac.kr (M. Kawasaki)

\begin{abstract}
Time-dependent plastic deformation behavior of nanocrystalline (nc) and coarse grained (cg) CoCrFeMnNi high-entropy alloys (HEAs) was systematically explored through a series of spherical nanoindentation creep experiments. High-pressure torsion (HPT) processing was performed for achieving nc microstructure in the HEA, leading to a reduction in grain size from $\sim 46 \mu \mathrm{m}$ for the as-cast state to $\sim 33 \mathrm{~nm}$ at the edge of HPT disks after 2 turns. Indentation creep tests revealed that creep deformation indeed occurs in both cg and nc HEAs even at room temperature and it is more pronounced with an increase in strain. The creep stress exponent, $n$, was estimated as $\sim 3$ for cg HEA and $\sim 1$ for nc HEA and the predominant creep mechanisms were investigated in terms of the values of $n$ and the activation volumes. Through theoretical calculations and comparison of the creep strain rates for nc HEA and a conventional face-centered-cubic nc metal $(\mathrm{Ni})$, the influence of sluggish diffusion on the creep resistance of nc HEA was analyzed. In addition, sharp indentation creep tests were performed for comparison purposes and the results confirmed that the use of a spherical indenter is clearly more appropriate for investigating the creep behavior of this HEA.
\end{abstract}

Keywords: creep, high-entropy alloy, high-pressure torsion, nanocrystalline metal. 


\section{Introduction}

High entropy alloys (HEAs) containing five or more elements in almost equal atomic proportions, exhibit high strengths, large strain hardening capability, high toughness, excellent resistance to high-temperature softening and creep, and good tribological properties. Hence, these are emerging as an exciting class of new structural materials and are drawing considerable attention in terms of research [1-8]. Despite a large number of principal elements, HEAs can often form simple solid solutions due to high configurational entropy [14]. It is well known that the mechanical performance of a material can be substantially enhanced by imparting a finer microstructure to it. In fact, nanocrystalline (nc) metals and alloys (having average grain size, $d<100 \mathrm{~nm}$ ) exhibit improved mechanical properties in comparison with their coarse-grained (cg) counterparts [9-13]. Then, it may be possible to achieve significantly improved materials by incorporating both the advantages of HEA and nc structure and, in fact, the authors' previous study [14] reported that nc CoCrFeMnNi HEA exhibits significant strengthening and reasonably high plasticity both of which were achieved by extensive grain refinement.

Hitherto, nc HEAs have been synthesized by magnetron sputtering (MS) [15], mechanical alloying (MA) [16-19], and high pressure torsion (HPT) [14,20,21]. Among them, HPT may be the most effective single-step processing to directly achieve excellent grain refinement in fully-dense bulk solids [22] because the sample synthesized by MS is only in thin film form and MA processing inevitably requires additional steps of consolidation. In addition, ability to achieve grain refinement in HEAs may be much higher in HPT than in MA, which can be supported by the fact that the average $d$ of HPT processed CoCrFeMnNi alloys ( 38-59 $\mathrm{nm}[14,21])$ is reported to be significantly smaller than that of the same component nc HEA processed through MA followed by spark plasma sintering ( $~ 50-200 \mathrm{~nm}$ [19]).

In the case of exceptionally fine-grained materials processed by severe plastic 
deformation (SPD) including HPT and equal-channel angular pressing (ECAP), the large fraction of grain boundaries (GBs) are often considered to be in a non-equilibrium state [21,23-30]. These severe-strain-induced non-equilibrium GBs contain an excess of extrinsic dislocations, higher energy, and larger free volume or vacancy concentration than in normal GBs in cg or annealed materials [27]. This, in turn, can result in significantly faster diffusion along non-equilibrium GBs than along normal GBs [25-27]. Due to this specific feature of a large portion of non-equilibrium GBs, materials processed by ECAP or HPT often exhibit diffusion-related deformation processes such as GB sliding and creep even at relatively low temperatures $[10,31,32]$. By comparison with ECAP, HPT processing has the advantage of introducing higher plastic strains and hence producing finer structures and a higher fraction of high-angle GBs [33-35], thereby facilitating the occurrence of diffusion-related phenomena.

HEAs are well known to exhibit improved diffusion resistance due to the different local cohesive energy at any lattice site as well as the lattice distortion arising from the difference in atomic size of the constituent elements [36,37]. Thus, the creep behavior of nc HEAs may conceivably be different from conventional nc metals and alloys as well. However, only a few studies have been performed thus far to examine the creep behavior of nc HEAs. Chang et al. [38] performed creep tests on nc (AlCrTaTiZr) $\mathrm{N}_{\mathrm{x}}$ coatings and investigated the influence of $\mathrm{N}$ addition on creep strain rate quantitatively. Ma et al. [15] studied the effects of peak load and loading rate on the creep deformation in a nc CoCrFeNiCu HEA thin film. However, almost no effort has been made to systematically indentify the creep mechanism of nc HEAs or to investigate the influence of sluggish diffusion on the creep properties of nc HEAs.

Based on this background, we explored time-dependent plastic deformation of nc HEAs in the present research through a series of spherical nanoindentation creep experiments. 
In general, the microstructure of HPT-processed material varies locally across the disk, therefore mechanical properties of HPT-processed metals have been extensively investigated through nanoindentation tests which require only a very small volume of material $[14,39,40]$. In this regard, nanoindentation creep testing [41-44] (especially, with a spherical tip; as we discuss later) is a promising way to successfully investigate small-scale creep behavior of HPT processed disks. Here, a CoCrFeMnNi HEA, which is one of the most widely studied HEA, was processed by HPT, and it was confirmed that the nc structure is readily achieved in the early stage of HPT processing. Thereafter, spherical nanoindentation creep experiments were performed on the nc HEA as well as their cg counterpart (i.e., as-cast HEA) for comparison purposes. The results revealed that the creep mechanism of nc HEA is different from that of cg HEA. By comparing the theoretically calculated creep strain rates of nc HEA to that of conventional face-centered-cubic (fcc) $\mathrm{nc} \mathrm{Ni}$, it is feasible to discuss the influence of sluggish diffusion on creep resistance of nc HEA.

\section{Experimental}

The alloy examined in this work was prepared by arc-melting a mixture of pure metals (purity >99 wt.\%) having a nominal composition of $\mathrm{Co}_{20} \mathrm{Cr}_{20} \mathrm{Fe}_{20} \mathrm{Mn}_{20} \mathrm{Ni}_{20}$ (in atomic \%) in a Ti-gettered high-purity Ar atmosphere. The ingots were remelted at least four times to promote chemical homogeneity. The melted alloys were then drop-cast into a mold with dimensions of $10 \mathrm{~mm} \times 10 \mathrm{~mm} \times 60 \mathrm{~mm}$.

The as-cast samples (disks having a radius of $5 \mathrm{~mm}$ and a thickness of $0.83 \mathrm{~mm}$ ) were subjected to HPT at room temperature (RT) with a pressure of $6.0 \mathrm{GPa}$ for a total of either 1/4 or 2 turns using a rotational speed of $1 \mathrm{rpm}$ [14]. To investigate the influence of straining on the quasi-static mechanical properties during HPT, the Vickers indentation hardness, $H_{\mathrm{V}}$, was measured using a HMV-2 microindenter (Shimadzu, Tokyo, Japan) at a peak load $P_{\max }$ of 980 
$\mathrm{mN}$ along diameters of the HEA disks processed by HPT. For each measurement position, the average value of $H_{\mathrm{V}}$ was determined from four separate measurements recorded at uniformly separated points displaced from the selected position by a distance of $0.15 \mathrm{~mm}$ [45]. The microstructures of the specimens were examined using an optical microscope (CK40M, Olympus, Tokyo, Japan), an electron backscattered diffraction (EBSD) instrument (FEI XL30 FEG, Philips, Cambridge, UK), and a transmission electron microscope (Tecnai F20, FEI Co., Hillsboro, OR). For the optical microscopy observations, the samples were mechanically polished to a mirror-like finish and etched with aqua regia solution which is a mixture of nitric acid and hydrochloric acid in a volume ratio of 1:3. The sample for the EBSD measurements was prepared by mechanical polishing with $0.05 \mu \mathrm{m}$ colloidal silica and subsequent electrolytic polishing at $58 \mathrm{~V}$ for $20 \mathrm{~s}$ in a mixture of $90 \%$ acetic and $10 \%$ perchloric acid at RT. Samples for transmission electron microscopy (TEM) at the vertical cross-sections of the HPT-processed disks were obtained through focused ion beam (FIB; Nova 200 NanoLab, FEI Co, Hillsboro, OR) milling. A thin layer was milled by FIB in the through-thickness direction at the edges of the processed HEA disks and lifted for TEM.

For the nanoindentation tests, electrolytic polishing at $58 \mathrm{~V}$ for $50 \mathrm{~s}$ in a mixture of $90 \%$ acetic and $10 \%$ perchloric acid was performed on mirror-finished samples to remove any possible surface damage induced during prior mechanical polishing. Nanoindentation creep experiments were performed at the edge regions, within $0.3 \mathrm{~mm}$ from the edge, of the HPT disks using a Nanoindenter-XP (formerly MTS; now Keysight, Santa Rosa, CA) with two different indenters, i.e. a Berkovich tip and a spherical tip with $R=38.6 \mu \mathrm{m}$ (which was estimated by Hertzian contact analysis [46] of the indentations made on fused quartz). During testing, the specimen was loaded to different $P_{\max }$ at a constant loading rate $(\mathrm{d} P / \mathrm{d} t)$ of 0.5 $\mathrm{mNs}^{-1}$, held at $P_{\max }$ for $1000 \mathrm{~s}$, and fully unloaded. More than 10 tests were conducted for each testing condition. 
For analyzing the applied strain variation within the HPT disk, finite-element analysis (FEA) simulation was performed using ABAQUS (HKS Inc., Pawtucket, RI) software. The geometries of the anvils were designed based on the quasi-constrained HPT conditions [47] and meshes were generated with 46,620 elements in the disk having initial $t$ and $r$ of $0.8 \mathrm{~mm}$ and $5.0 \mathrm{~mm}$, respectively. A high friction coefficient of 0.7 was applied between the anvil and the disk to maintain a reasonable traction between them [47]. The material parameters used for the present simulation were based on the flow curve reported for this specific HEA [48].

\section{Results}

\subsection{Achievement of nanostructures by HPT process}

During the HPT, the equivalent von Mises strain $\varepsilon_{\text {eq }}$ imposed on the disk is given by the relationship [49]:

$$
\varepsilon_{e q}=\frac{2 \pi N r}{\sqrt{3} t}
$$

where $r$ and $t$ are the radius and thickness of the disk, respectively, and $N$ is the number of torsional revolutions. In Fig. 1, the changes in $H_{\mathrm{V}}$ are represented as a function of $\varepsilon_{\text {eq }}$ calculated from Eq. (1), and $H_{\mathrm{V}}$ of the as-cast sample $(1.75 \pm 0.04 \mathrm{GPa})$ is also displayed. Note that $H \mathrm{v}$ in the figure is the Meyer's hardness which is equivalent to $P_{\max }$ divided by projected area instead of the surface area (that is typically used for Vickers hardness). The inset of Fig. 1 provides the FEA simulation results for the $\varepsilon_{\text {eq }}$ distribution over the one-quarter disk surface after $\sim 1 / 4$ turn that are illustrated through a series of colors representing the different listed strains. As shown in the figure, the values of simulated $\varepsilon_{\mathrm{eq}}$ at the edge of disk match well with those calculated according to Eq. (1).

From Fig. 1, three points are noteworthy. First, in the region of $\varepsilon_{\text {eq }} \sim 5-7, H_{\mathrm{V}}$ values for $N=1 / 4$ overlap reasonably well with those for $N=2$, implying that the two cases 
examined here $(N=1 / 4$ and 2$)$ can cover a wide range of straining in the HPT process. Second, at the early stage of HPT $\left(\varepsilon_{\mathrm{eq}}<5\right)$ the hardness of the processed disks increases rapidly with $\varepsilon_{\mathrm{eq}}$. After $1 / 4$ turn, the $H_{\mathrm{V}}$ at the disk edges (where $\varepsilon_{\mathrm{eq}} \sim 5$ ) reaches $4.70 \pm 0.04$ $\mathrm{GPa}$ which is almost three times higher than for the as-cast specimen $(1.75 \pm 0.04 \mathrm{GPa})$. Third, with further increasing of $\varepsilon_{\mathrm{eq}}$, the $H_{\mathrm{V}}$ values throughout the disks increase moderately and then become saturated at around 5.2 GPa. These results demonstrate that this alloy experiences a significant strain hardening in the early stage of HPT processing and the strengthening exhibits saturation behavior around $\varepsilon_{\mathrm{eq}}$ of $\sim 20$.

The inhomogeneous distribution of $H_{\mathrm{V}}$ in Fig. 1 supports the expectation that microstructural evolution will occur most significantly in the peripheral regions of the HPT processed disks. Fig. 2 shows representative microstructures of the as-cast sample and the edges of the HPT disks for $N=1 / 4$ and 2 turns. Fig. 2a is an optical micrograph showing the dendritic microstructure in the as-cast sample. It was reported that the dendritic areas are slightly enriched with $\mathrm{Co}, \mathrm{Cr}$, and $\mathrm{Fe}$, whereas the interdendritic areas have slightly higher $\mathrm{Ni}$ and Mn [50]. To acquire information on the true grain size instead of the dendrite size, EBSD analysis was conducted on the as-cast sample and a representative image combining index of quality and grain orientation map is shown in Fig. $2 \mathrm{~b}$ where the average grain size, $d$, was determined as $\sim 46 \mu \mathrm{m}$. After HPT processing, it was necessary to use TEM analysis to measure the grain sizes at the edge regions of the HPT disks. Figs. $2 \mathrm{c}$ and $2 \mathrm{~d}$ show brightfield (BF) images and selected area diffraction (SAD) patterns of the disk edges for $N=1 / 4$ and 2, respectively. These micrographs show there are equiaxed fine grains with $d$ of $\sim 49$ and $\sim 33 \mathrm{~nm}$ for $1 / 4$ and 2 turns, respectively, which are similar to the data previously reported under the same conditions [14]. The SAD patterns for both samples confirm a single-phase fcc structure, indicating to the absence of any phase transformation during the HPT processing, which is consistent with the x-ray diffraction data in the authors' previous study 
[14]. From these results, it is concluded that nc structure develops in the early stages of HPT processing itself, and thereafter a gradual reduction in $d$ occurs with further turning. Considering the plateau in hardness (see Fig. 1), it is reasonable to believe that the grain refinement reaches a saturation level at the disk edge for $N=2$.

\subsection{Spherical indentation creep test}

To compare the creep responses of nc and cg HEAs, modified constant-load nanoindentation creep experiments with a spherical indenter $[43,44]$ were performed at the edges of the HPT processed disks as well as the as-cast sample. For classifying the data from different $P_{\max }$ under elastic and elastic-plastic regimes, we conducted normal quasi-static nanoindentation tests without peak-load holding. Fig. 3 shows representative quasi-static nanoindentation load-displacement $(P-h)$ curves of cg (as-cast) and nc HEAs. The $P$ - $h$ curves obtained at relatively low $P_{\max }$ (see blue open circle data in the curves) show that the loading part of each curve is completely reversed upon unloading, indicating that the deformation is purely elastic and follows the Hertzian contact theory [46]. In the case of cg HEA, sudden displacement excursions (often referred to as "pop-ins") were observed at $P \sim 5 \mathrm{mN}$ during the loading sequence, and the displacements were not fully recovered on unloading. This suggests that yielding of the cg HEA under quasi-static loading occurs at a $P$ of around $5 \mathrm{mN}$. By contrast, the nc HEAs exhibit smooth elastic-to-plastic transition behavior (that may be due to the accumulation of small pop-ins) which correspond to the point where the experimental $P$ - $h$ data deviate from the Hertzian curves. From Fig. 3, we can determine that the transition of nc HEAs occurs at $P$ around 8 and $10 \mathrm{mN}$ for $d$ of $\sim 49$ and $33 \mathrm{~nm}$, respectively.

Figs. $4 \mathrm{a}$ and $4 \mathrm{~b}$ show the representative $P-h$ curves recorded during the spherical indentation creep tests performed in the elastic and elastic-plastic regimes, respectively. In 
both regimes, $h$ increases during the holding sequence so that creep occurs. Especially in the elastic regime, an increase in $h$ during the holding sequence can be clearly seen and this timedependent deformation is mostly not recovered and remains upon unloading, thereby suggesting that the observed creep behavior is primarily plastic in nature and the possible contribution of anelasticity to the creep deformation is probably negligible. From the Hertzian contact analysis [46] of the loading curve in Fig. 4a, the plane-strain moduli of the samples, $E_{\mathrm{s}} /\left(1-v_{\mathrm{s}}^{2}\right)$, where $E_{\mathrm{s}}$ and $v_{\mathrm{s}}$ are Young's modulus and Poisson's ratio of the sample, respectively, were estimated as $193 \pm 5$ and $173 \pm 4 \mathrm{GPa}$ for cg and nc HEAs, respectively. Note that the value of cg HEA is in reasonable agreement with the literature data ( 182 GPa) [51]. This confirms that creep plasticity can be generated at RT even if the stress state underneath the indenter is less than the global yield strength.

The total creep displacements, $h_{\text {creep}}$, (that is the maximum value of $h-h_{0}$ at $1000 \mathrm{~s}$, hereinafter subscript 0 indicates the onset of creep) versus indentation strain at the onset of creep, $\left(\varepsilon_{\mathrm{i}}\right)_{0}$, for nc and cg HEAs are summarized in Fig. 5. In the case of spherical indentation, indentation strain, $\varepsilon_{i}$, is often described as $0.2 a / R_{\mathrm{i}}$, where $a$ is the contact radius and $R_{\mathrm{i}}$ is the radius of the spherical indenter [46]. In the plot, the average values of stain estimated from elastic-to-plastic transition, $\varepsilon_{\mathrm{y}}$, for nc and cg HEAs are represented with vertical lines. While the creep behavior is less pronounced in the elastic regime, the $h_{\text {creep }}$ values in the elasticplastic regime are relatively large and increase dramatically with $\varepsilon_{i}$.

As a first step to quantitatively analyze the creep behavior, the indentation creep strain, $\varepsilon_{\text {creep }}$, is quantified as $0.2\left(a-a_{0}\right) / R$ where $a$ is estimated as $a=\sqrt{2 h R-h^{2}}$ in simple consideration of the contact geometry of a spherical indentation [43]. Note that in this study, a measured $h$ is used for simplicity instead of the precise value of contact depth, $h_{\mathrm{c}}$. The examples of calculated results for nc and cg HEAs are described in the insets of Fig. 6 as a function of holding time ( $\left.t_{\text {hold }}\right)$. The $\varepsilon_{\text {creep }}$ Vs. $t_{\text {hold }}$ curves are somewhat analogous to the early 
stages of the typical high-temperature creep curves, consisting of both transient and steadystate creep regimes. It is also noteworthy that the amount of $\varepsilon_{\text {creep }}$ increases significantly with $P_{\max }$, which indicates that the observed creep behavior is not an artifact caused by thermal drift that is independent of load $[43,52,53]$.

To estimate the indentation strain rate, $\dot{\varepsilon}_{i}$, for a spherical indentation, $\varepsilon_{\text {creep }}$ vs. $t_{\text {hold }}$ curves were fitted according to Garofalo's mathematical fitting equation which was originally developed for uniaxial creep tests,

$$
\varepsilon_{i}-\left(\varepsilon_{i}\right)_{0}=\varepsilon_{\text {creep }}=\alpha\left(1-e^{-r t_{\text {hold }}}\right)+\omega t_{\text {hold }},
$$

where $\alpha, \omega$ and $r$ are creep constants. By differentiating the fitted equation with respect to $t_{\text {hold }}$, the change in $\dot{\varepsilon}_{i}$ can be obtained as a function of $t_{\text {hold. }}$ Applying the empirical relation between unaixial strain rate, $\dot{\varepsilon}_{u}$, and $\dot{\varepsilon}_{i}$ of $\dot{\varepsilon}_{u} \sim 0.01 \dot{\varepsilon}_{i}$ [54], the variations in $\dot{\varepsilon}_{u}$ with $t_{\text {hold }}$ for nc and cg HEAs are plotted in the main plots of Fig. 6. These results suggest the possible attainment of steady-state (hereinafter called "quasi-steady-state, QSS") during indentation.

\section{Discussion}

\subsection{Stress exponent, activation volume, and creep mechanism}

Estimating the predominant creep mechanism is essential for better understanding of the creep behavior of HEAs. It is well accepted that the creep stress exponent, $n$ (= $\partial \ln \dot{\varepsilon}_{S S} / \partial \ln \sigma$ where $\dot{\varepsilon}_{S S}$ is the steady-state creep rate and $\sigma$ is the applied stress), is a useful indicator for deducing the mechanism such that $n=1$ for diffusion creep such as NabarroHerring creep (by lattice diffusion) and Coble creep (by GB diffusion), $n=2$ for GB sliding, and $n=3-8$ for dislocation creep [55,56]. For comparison purposes, one can find summary tables of the $n$ and other creep properties of a conventional nc fcc metal (Ni) estimated from various experiments $[43,57]$ 
In this study, from spherical indentation creep data the values of $n$ can be directly obtained by using the equation: $n=\partial \ln \dot{\varepsilon}_{\mathrm{QSS}} / \partial \ln \sigma$, where $\dot{\varepsilon}_{\mathrm{QSS}}$ is the QSS creep rate. The $\dot{\varepsilon}_{\text {QSS }}$ was determined at $t_{\text {hold }}=1000 \mathrm{~s}$ while $\sigma$ is estimated from $H$ at $t_{\text {hold }}=1000 \mathrm{~s}$ by Tabor's empirical law, $\sigma \sim H / C$, where $C$ is the constraint factor which is typically $\sim 3$ for metals [46]. Note that the value of $\sigma$ is continuously varying during a constant-load indentation creep test. The variations in $\dot{\varepsilon}_{\mathrm{QSS}}$ with $\sigma$ for nc and cg HEAs are summarized in Fig. 7. From the slope of linear fitting of the average points in the logarithmic $\dot{\varepsilon}_{\text {OSS }}$ and $\sigma$ plots, $n$ was determined as $\sim 1$ for the nc HEAs and $\sim 3$ for the cg HEA. This implies that the creep is mainly governed by diffusion in nc HEAs whereas, by contrast, the time-dependent deformation of the cg HEA is dislocation mediated.

Further insight into the mechanism of creep is obtained by estimating the value of the activation volume, $V^{*}$, which is given by:

$$
V^{*}=\sqrt{3} k T\left(\frac{\partial \ln \dot{\varepsilon}_{\mathrm{QSS}}}{\partial \sigma}\right)
$$

where $k$ is Boltzmann's constant. It was shown earlier that the value of $V^{*}$ varies by orders of magnitude for different rate-limiting processes [58] with typical values of $V^{*}$ in the ranges from $\sim 100 b^{3}-1000 b^{3}$ for dislocation glide in fcc metals down to $\sim b^{3}$ for diffusion either along the GB or through the crystalline lattice [59-61].

The values of $V^{*}$ determined from the slopes of the linear fits of logarithmic $\dot{\varepsilon}_{\text {QSS }}$ vs. linear $\sigma$ are displayed in Fig. 8. Here, the Burgers vector $b$ for the alloy was calculated as $b=l \times \sqrt{2} / 2 \approx 2.25 \times 10^{-10} \mathrm{~m}$ where $l$ is the lattice parameter $(\sim 3.60 \AA$ [14]). For cg HEA, the calculated $V^{*}$ is $\sim 4.6 b^{3}$ which is smaller than $V^{*}$ for the forest dislocation cutting mechanism in conventional metals [58,59]. It was suggested by Wang et al. [62] for shallow indentations that diffusion along the interface between the indenter tip and the sample surface may 
additionally play an important role, whereas for deep indentations the role of interfacial diffusion becomes negligible and conventional creep mechanisms related to microstructural activities are predominant. In this regard, the smaller-than-typical value of $V^{*}$ for cg HEA may indicate that interfacial diffusion continues to play a role and thus reduces $V^{*}$ while the main governing mechanism is dislocation creep.

In Fig. 8, the $V^{*}$ for nc HEAs is determined as $\sim 0.8 b^{3}$, which means that the predominant creep mechanism of nc HEAs may be diffusion creep, although there are small primary creep stages (see Fig. 6) that are barely observed in the high-temperature diffusion creep curves. In this regime and for a given $\sigma$, the steady-state creep rate $\dot{\varepsilon}_{\mathrm{SS}}$ is the sum of the creep rate by lattice diffusion, $\left(\dot{\varepsilon}_{\mathrm{SS}}\right)_{l}$ and by GB diffusion $\left(\dot{\varepsilon}_{\mathrm{SS}}\right)_{G B}$.

Since $\left(\dot{\varepsilon}_{\mathrm{SS}}\right)_{l}$ is negligibly small vis-à-vis $\left(\dot{\varepsilon}_{\mathrm{SS}}\right)_{G B}$, the diffusion creep deformation of nc materials is mainly governed by GB diffusion and its related deformation mechanisms such as Coble creep, GB sliding, GB migration, and GB rotation. Note that these $V^{*}$ are an order of magnitude smaller than $\sim 8 b^{3}$ estimated from strain-rate sensitivity tests of the nc HEAs at RT [14]. The latter correspond to the dislocation-mediated flow. Instead, the values obtained in this study are closer to those for the heterogeneous nucleation of dislocations during nanoindentation of a metal $\left(\sim 0.5 b^{3}\right)$ where vacancies can play a significant role [63].

\subsection{Sluggish diffusion effect on creep behavior}

As discussed above, the creep deformation in nc HEAs may be primarily governed by GB diffusion and related phenomena. Distinct characteristics of HEAs such as sluggish diffusion leads to the expectation that creep properties of this fcc nc HEAs are different from those of conventional fcc nc metals. Thus, it is constructive to make a direct comparison. A constitutive equation for diffusion creep deformation in nc materials is given as [64]: 


$$
\dot{\varepsilon}_{\mathrm{SS}} \approx\left(\dot{\varepsilon}_{\mathrm{SS}}\right)_{G B} \approx \frac{50 \sigma b^{4}}{k T d^{3}} D_{\mathrm{GB}}
$$

where $k$ is Boltzmann constant, $T$ is the absolute temperature, and $D_{\mathrm{GB}}$ is the grain boundary diffusivity that is given as an Arrhenius-type equation:

$$
D_{\mathrm{GB}}=D_{0, G B} \exp \left(-\frac{Q_{G B}}{R T}\right) \text {. }
$$

Here $D_{0, G B}$ is the pre-exponential factor, $R$ is the gas constant, and $Q_{G B}$ is the activation energy for GB diffusion. As mentioned in the introduction section, SPD processed ultrafinegrained (ufg) metals are known to have a large volume of non-equilibrium GBs which contain a high concentration of extrinsic dislocations [65] giving a larger excess free energy, and hence may exhibit enhanced diffusivities [27-29]. In a recent study [28], the values of $D_{0, G B}$ and $Q_{G B}$ for SPD processed ufg Ni were experimentally determined as $1.2 \times 10^{-8} \mathrm{~m}^{2} / \mathrm{s}$ and $67 \mathrm{~kJ} / \mathrm{mol}$, respectively. By putting these values and $T=298 \mathrm{~K}$ and $d=33 \mathrm{~nm} \mathrm{[28]} \mathrm{into}$ Eqs. (5) and (6), the theoretical $\sigma$ dependence on the $\dot{\varepsilon}_{\mathrm{SS}}$ of nc Ni can be estimated and this is represented by the dashed black line in Fig. 7. As seen, the experimentally obtained $\dot{\varepsilon}_{\mathrm{QSS}}$ of nc HEAs is about four or five orders of magnitude smaller than the theoretical $\dot{\varepsilon}_{\mathrm{SS}}$ of nc Ni. This implies that nc HEAs may have much higher resistance to creep deformation which is consistent with the well-known sluggish diffusion in HEAs.

To further analyze the characteristics of the sluggish diffusion on creep, it is necessary to estimate the incremental increase in $Q_{G B}$ by this effect, i.e. $\Delta Q_{G B}$. Since it is difficult to calculate $\Delta Q_{G B}$ in consideration of the sluggish diffusion in the lattice, it is necessary to adopt an indirect approach by using the ratio of $Q_{G B}$ to $Q_{l}$ where $Q_{l}$ is the activation energy for the lattice diffusion. Brown and Ashby [66] reported that for fcc metals (such as $\mathrm{Ni}, \mathrm{Cu}, \mathrm{Pb}, \mathrm{Au}$, $\beta$-Co, and $\gamma-\mathrm{Fe}$ ), the values of $Q_{G B} / Q_{l}$ are almost constant and close to $\sim 0.6$. From this, we calculate $\Delta Q_{l}$ by sluggish diffusion first and then estimate $\Delta Q_{G B}$ by $\sim 0.6 \Delta Q_{l}$. 
Recently, Chang et al. [37] suggested that the three major factors determining $\Delta Q_{l}$ in multi-component alloys including HEAs are the strain energy of lattice distortion, the packing density of atoms, and the cohesive energy of atoms which can be re-described as

$$
\Delta Q_{l}=\left(\Delta U_{\text {strain }}+\Delta H_{\text {mix }}\right) \frac{S_{m}}{S}
$$

Here, $\Delta U_{\text {strain }}$ is the lattice distortion strain energy, $\Delta H_{\text {mix }}$ is the enthalpy of mixing which corresponds to the change in cohesive energy of the atoms, and $S_{m}$ and $S$ are the packing densities of a multi-component alloy and a unitary alloy, respectively. The $S_{m}$ normalized by $S$ in Eq. (6) indicates the extent of difficult since the diffusion becomes more difficult in a solid having higher packing density [37]. Since it is not feasible to simply define the solvent atoms versus the solute atoms in equiatomic HEAs and thus Eshelby's elasticity approach [67] cannot be used directly to estimate the value of $\Delta U_{\text {strain, }}$ Ye et al. [68] proposed a geometric approach in which the average lattice constant of the alloy is linked to a few critical geometric variables such as atomic size, atomic fraction, and packing density. Using the geometric approach [68], the $\Delta U_{\text {strain }}$ stored in HEAs can be expressed as:

$$
\Delta U_{\text {strain }}=\frac{9}{2} \bar{K} \Omega_{\text {tot }} u_{\mathrm{e}}
$$

where $\bar{K}$ and $\Omega_{\text {tot }}$ are the average bulk modulus and the total atomic volume of the alloy, respectively, and $u_{\mathrm{e}}$ is the dimensionless elastic energy storage.

For the HEA examined in this study, the $u_{\mathrm{e}}$ of Eq. (7) is $9.67 \times 10^{-4}$ [68] and the bulk modulus $K$ and atomic volume $\Omega$ of each constituent element [69] are listed in Table 1 . The $\Delta H_{\text {mix }}$ of Eq. (6) is determined as:

$$
\Delta H_{\text {mix }}=4 \sum_{i=1, i \neq j}^{n} \Delta H_{i j}^{m i x} X_{i} X_{j}
$$

where $X_{\mathrm{i}}$ is the molar ratio of the $i$ th element and $\Delta H_{i j}{ }^{\text {mix }}$ is the enthalpy of mixing between 
the $i$ th and $j$ th elements [70]. Table 2 summarizes the values of $\Delta H_{i j}{ }^{\text {ix }}$ for each combination of constituent elements in the examined HEA. Since the change in packing density is already considered in the geometric model, Eq. (6) can be modified to

$$
\Delta Q_{l}=\Delta U_{\text {strain }}+\Delta H_{\text {mix }} \frac{S_{m}}{S}
$$

According to Eqs. (8) and (9), $\Delta U_{\text {strain }}$ and $\Delta H_{\text {mix }}$ of the CoCrFeMnNi HEA can be determined as $\sim 34.4$ and $-4.2 \mathrm{~kJ} / \mathrm{mol}$, respectively. Then, with $S_{\mathrm{m}}=0.802$ for the examined HEA [68] and $S=0.74$ for ideal fcc lattice, $\Delta Q_{l}$ is finally estimated as $\sim 30 \mathrm{~kJ} / \mathrm{mol}$ by Eq. (9). Recently, Tsai et al. [36] empirically investigated $\Delta Q_{l}$ of each constituent element in the $\mathrm{CoCrFeMnNi}$ system and reported that the values are in the range of $18-32 \mathrm{~kJ} / \mathrm{mol}$. This implies that using Eq. (9) for estimating the value of $\Delta Q_{l}$ is a reasonable approach. From this, $\Delta Q_{G B}$ by sluggish diffusion was estimated as $0.6 \Delta Q_{l}$ to give $\sim 17 \mathrm{~kJ} / \mathrm{mol}$.

Since there is no principal element in this HEA, the slowest diffusing element, that is, $\mathrm{Ni}$, is expected to be rate controlling in diffusion-related deformation $[3,4,71]$. Therefore, it is reasonable to estimate the theoretical $\dot{\varepsilon}_{\mathrm{SS}}$ for the diffusion creep mechanism of nc HEA on the basis of the diffusion-related parameters of Ni. The only difference is that $Q_{G B}$ of Eq. (5) is no longer $Q_{G B}$ for $\mathrm{Ni}$ (without the sluggish diffusion effect) but rather it is the sum of $Q_{G B}$ for $\mathrm{Ni}\left(\sim 67 \mathrm{~kJ} / \mathrm{mol}\right.$ for SPD processed ufg $\mathrm{Ni}$ [28]) and $\Delta Q_{G B}$ by the sluggish diffusion effect calculated above $(\sim 17 \mathrm{~kJ} / \mathrm{mol})$ to thereby give $\sim 84 \mathrm{~kJ} / \mathrm{mol}$. Putting this value and $T=298 \mathrm{~K}$ and $d=33 \mathrm{~nm}$ into Eqs. (5) and (6) gives the theoretical values for the $\dot{\varepsilon}_{\mathrm{Ss}}$ vs. $\sigma$ of nc HEA, which are displayed as a red dotted line in Fig. 7. As shown in the figure, the "theoretical" relation of $\dot{\varepsilon}_{\mathrm{SS}}$ vs. $\sigma$ for the diffusion creep of nc HEA is in reasonable agreement with the experimental results. This implies that the much smaller $\dot{\varepsilon}_{\mathrm{SS}}$ in nc HEA vis-à-vis that of nc 
Ni may be due to the change in $Q_{G B}$ induced by the sluggish diffusion. The observed small discrepancy between experimental and theoretical results for nc HEAs may be associated with the assumptions inherent in the analysis. For example, $\dot{\varepsilon}_{i}$ is converted to $\dot{\varepsilon}_{u}$ by the empirical relation $\dot{\varepsilon}_{u} \sim 0.01 \dot{\varepsilon}_{i}$ based on a study of nc Ni [54] but this may not be valid for other nc materials and also it may vary with the loading conditions $[54,72,73]$.

To summarize, the above results lead to two important characteristics in creep behavior of nc HEAs. First, the room temperature creep of nc HEA is predominantly controlled by GB diffusion. Second, nc HEA exhibits much higher creep resistance as compared to conventional fcc nc metal due mainly to sluggish diffusion. It is noteworthy that, although there can be an inevitable difference in diffusion creep results between experiments and theoretical predictions, the above scenario still holds valid because it was shown that the experimental data for diffusion creep support the theoretical model to within a factor of (at most) 4 [74].

\subsection{Merits of the spherical indentation creep tests}

We performed the creep experiments in this study using a spherical indenter whereas most of the nanoindentation experiments--including indentation creep tests--are conducted with a three-sided pyramidal indenter such as a Berkovich tip [42,75-77]. This is because, some issues related to the sharp tip geometry arise in the latter $[43,44]$. For example, both the characteristic indentation strain and stress underneath a given sharp tip are unique and independent of $h_{\text {creep }}$ because of the geometrical self-similarity of the indenter, which makes it virtually impossible to define the change in strain rate as a function of stress.

To demonstrate this, we investigated the creep exponent $n$ of the nc HEA through typical constant-load sharp indentation creep tests using a Berkovich indenter. For sharp indentation, $\dot{\varepsilon}_{i}$ is given as $(\mathrm{d} h / \mathrm{d} t) h^{-1}$ in which the displacement rate $(\mathrm{d} h / \mathrm{d} t)$ is typically 
calculated by fitting the $h_{\text {creep }}-t_{\text {hold }}$ curve according to an empirical fitting equation $[44,78]$ :

$$
h(t)=h_{0}+A\left(t_{\text {hold }}\right)^{\kappa}+B t_{\text {hold }}
$$

where $A, B$ and $\kappa$ are fitting constants. Then, $\dot{\varepsilon}_{i}$ can be converted to $\dot{\varepsilon}_{u}$ by $\dot{\varepsilon}_{u} \sim 0.01 \dot{\varepsilon}_{i}$ [54]. The continuous change in the stress during the holding period at $P_{\max }$ was estimated as $H / C$ where $H$ was roughly calculated as $P_{\max } /\left(24.5 h^{2}\right)[79,80]$ and $C \sim 3$. Fig. 9 provides representative examples of the data obtained from the Berkovich indentation creep tests made at three different $P_{\max }(10,50$ and $100 \mathrm{mN})$. Similar to the Berkovich creep indentation data in the literature $[43,75,76]$, somewhat implausible behavior can be identified in the figure; i.e., first, the estimated $n$ is very high and second, it increases with $P_{\max }: n$ is $14.34 \pm 6.24$ for 10 $\mathrm{mN}, 18.34 \pm 8.52$ for $50 \mathrm{mN}, 34.27 \pm 10.68$ for $100 \mathrm{mN}$. Considering the fact that $H$ at the onset of creep exhibits a clear trend of indentation size effect (ISE), it appears that $n$ increases with reducing $\sigma$. This trend cannot be explained by classical creep theory in conventional metals where a higher $\sigma$ regime corresponds to higher $n$. Thus, $n$ values of power-law breakdown regime (highest $\sigma$ regime) are higher than those of power-law creep regime (intermediate $\sigma$ regime) and the values are the lowest for the low $\sigma$ regime (diffusion creep or Harper-Dorn creep) [81]. These results confirm that the spherical nanoindentation creep tests adopted here may produce more reliable creep data than the sharp indentation tests that are typically used, at least for the nc HEA tested in this study.

\section{Conclusions}

In the present study, the nanoscale creep behavior of nc and cg CoCrFeMnNi HEAs was systematically investigated in nanoindentation creep experiments with a spherical tip. The major results of this investigation are as follows.

1. The nc HEAs were successfully synthesized through HPT, which leads to a significant grain refinement after 2 turns and gives a major increase in hardness. 
2. Nanoindentation creep experiments reveal that both nc and cg HEAs undergo creep at room temperature. The creep displacement and strain rate of HEAs were increased with the applied strain at the onset of creep.

3. Both the creep stress exponent,t $n$, estimated from the quasi-steady-static strain rate and stress and the activation volume $V^{*}$ suggest that the predominant time-dependent deformation mechanism shifts from dislocation mediated in cg HEA to GB diffusion and its related phenomena in nc HEAs.

4. A theoretical estimate of the creep rate in nc HEA and its comparison with that in conventional nc Ni suggests that creep resistance of nc HEA is significantly enhanced due to sluggish diffusion in HEAs.

5. A comparison of the creep data obtained with spherical and Berkovich tips shows that the former is more appropriate for investigating the creep behavior.

\section{Acknowledgements}

The research of DHL, MYS, YZ, JIJ was supported in part by the National Research Foundation of Korea (NRF) grant funded by the Korea government (MSIP) (No.2013R1A1A2A10058551), and in part by the Human Resources Development program of the Korea Institute of Energy Technology Evaluation and Planning (KETEP) grant funded by the Korea government (MOTIE) (No. 20134030200360). The work of MK was supported by the NRF Korea funded by MoE under grant No. NRF-2014R1A1A2057697. The work of TGL was supported by the National Science Foundation of the United States under Grant No. DMR-1160966 and by the European Research Council under ERC Grant Agreement No. 267464-SPDMETALS. The work of ZPL was supported by National Natural Science Foundation of China under grant No. 51531001003. 


\section{References}

1. B. Cantor, I.T.H. Chang, P. Knight, A. Vincent, Microstructural development in equiatomic multicomponent alloys, Mater. Sci. Eng. A, 375 (2004) 213-218.

2. J.-W. Yeh, S.-K. Chen, S.-J. Lin, J.-Y. Gan, T.-S. Chin, T.-T. Shun, C.-H. Tsau, S.-Y. Chang, Nanostructured high-entropy alloys with multiple principal elements, Adv. Eng. Mater. 6 (2004) 299-303.

3. B.S. Murty, J.-W. Yeh, S. Ranganathan: High-Entropy Alloys, ButterworthHeinemann, London, UK, 2014.

4. Y. Zhang, T.T. Zuo, Z. Tang, M.C. Gao, K.A. Dahmen, P.K. Liaw, Z.P. Lu, Microstructures and properties of high-entropy alloys, Prog. Mater. Sci. 61 (2014) 193.

5. J.Y. He, W.H. Liu, H. Wang, Y. Wu, X.J. Liu, T.G. Nieh, Z.P. Lu, Effects of Al addition on structural evolution and tensile properties of the FeCoNiCrMn highentropy alloy system, Acta Mater. 62 (2014) 105-113.

6. O.N. Senkov, J. Scott, S. Senkova, Microstructure and elevated temperature properties of a refractory TaNbHfZrTi alloy, J. Mater. Sci. 47 (2012) 4062-4074.

7. F. Otto, A. Dlouhý, C. Somsen, H. Bei, G. Eggeler, E.P. George, The influences of temperature and microstructure on the tensile properties of a $\mathrm{CoCrFeMnNi}$ highentropy alloy, Acta Mater. 61 (2013) 5743-5755.

8. Z. Wu, H. Bei, G.M. Pharr, E.P. George, Temperature dependence of the mechanical properties of equiatomic solid solution alloys with face-centered cubic crystal structures, Acta Mater. 81 (2014) 428-441.

9. H. Gleiter, Nanocrystalline materials, Prog. Mater. Sci. 33 (1989) 223-315.

10. R. Valiev, Nanostructuring of metals by severe plastic deformation for advanced properties, Nat. Mater. 3 (2004) 511-516.

11. M.A. Meyers, A. Mishra, D.J. Benson, Mechanical properties of nanocrystalline materials, Prog. Mater. Sci. 51 (2006) 427-556.

12. M. Dao, L. Lu, R.J. Asaro. J.T.M. De Hosson, E. Ma, Toward a quantitative understanding of mechanical behavior of nanocrystalline metals, Acta Mater. 55 (2007) 4041-4065.

13. T. Zhu, J. Li, Ultra-strength materials, Prog. Mater. Sci. 55 (2010) 710-757.

14. D.-H. Lee, I.-C. Choi, M.-Y. Seok, J. He, Z. Lu, J.-Y. Suh, M. Kawasaki, T.G. Langdon, J.-i. Jang, Nanomechanical behavior and structural stability of a nanocrystalline CoCrFeNiMn high-entropy alloy processed by high-pressure torsion, J. Mater. Res. 30 (2015) 2804-2815.

15. Y. Ma, G.J. Peng, D.H. Wen, T.H. Zhang, Nanoindentation creep behavior in a $\mathrm{CoCrFeCuNi}$ high-entropy alloy film with two different structure states, Mater. Sci. Eng. A 621 (2015) 111-117.

16. K.B. Zhang, Z.Y. Fu, J.Y. Zhang, J. Shi, W.M. Wang, H. Wang, Y.C. Wang, Q.J. Zhang, Nanocrystalline CoCrFeNiCuAl high-entropy solid solution synthesized by mechanical alloying, J. Alloys Compd. 485 (2009) 31-34.

17. S. Varalakshmi, M. Kamaraj, B.S. Murty, Processing and properties of nanocrystalline CuNiCoZnAlTi high entropy alloys by mechanical alloying, Mater. Sci. Eng. A 527 (2010) 1027-1030.

18. S. Praveen, B.S. Murty, S. Kottada Ravi, Alloying behavior in multi-component AlCoCrCuFe and NiCoCrCuFe high entropy alloys, Mater. Sci. Eng. A 534 (2012) 83-89.

19. W. Ji, W. Wang, H. Wang, J. Zhang, Y. Wang, F. Zhang, Z. Fu, Alloying behavior and novel properties of $\mathrm{CoCrFeNiMn}$ high-entropy alloy fabricated by mechanical 
alloying and spark plasma sintering, Intermetall. 56 (2015) 24-27.

20. Q.H. Tang, Y. Huang, Y.Y. Huang, X.Z. Liao, T.G. Langdon, P.Q. Dai, Hardening of an $\mathrm{A} 10.3 \mathrm{CoCrFeNi}$ high entropy alloy via high-pressure torsion and thermal annealing, Mater. Lett. 151 (2015) 126-129.

21. B. Schuh, F.M. Martin, B. Völker, E.P. George, H. Clemens, R. Pippan, A. Hohenwarter, Mechanical properties, microstructure and thermal stability of a nanocrystalline CoCrFeMnNi high-entropy alloy after severe plastic deformation, Acta Mater. 96 (2015) 258-268.

22. T.G. Langdon, Twenty-five years of ultrafine-grained materials: Achieving exceptional properties through grain refinement, Acta Mater. 61 (2013) 7035-7059.

23. R.V. Valiev, V.Y. Gertsman, O.A. Kaibyshev, Grain boundary structure and properties under external influences, Phys. Stat. Sol. (a) 97 (1986) 11-56.

24. A.A. Nazarov, A.E. Romanov, R.Z. Valiev, On the structure, stress fields and energy of non equilibrium grain boundaries, Acta Metall. Mater. 41 (1993) 1033-1040.

25. Y.T. Kolobov, G.P. Grabovetskaya, M.B. Ivanov, A.P. Zhilyaev, R.Z. Valiev, Grain boundary diffusion characteristics of nanostructured nickel, Scripta Mater. 44 (2001) 873-878.

26. T. Fujita, Z. Horita, T.G. Langdon, Characteristics of diffusion in Al-Mg alloys with ultrafine grain sizes, Phil. Mag. A 82 (2002) 2249-2262.

27. Z.B. Wang, K. Lu, G. Wilde, S.V. Divinski, Interfacial diffusion in $\mathrm{Cu}$ with a gradient nanostructured surface layer, Acta Mater. 58 (2010) 2376-2386.

28. S.V. Divinski, G. Reglitz, H. Rösner, Y. Estrin, G. Wilde, Ultra-fast diffusion channels in pure $\mathrm{Ni}$ severely deformed by equal-channel angular pressing, Acta Mater. 59 (2011) 1947-1985.

29. X. Sauvage, G. Wilde, S.V. Divinski, Z. Horita, R.Z. Valiev, Grain boundaries in ultrafine grained materials processed by severe plastic deformation and related phenomena, Mater. Sci. Eng. A 540 (2012) 1-12.

30. P. Kumar, M. Kawasaki, T.G. Langdon, Review: Overcoming the paradox of strength and ductility in ultrafine-grained materials at low temperatures, J. Mater. Sci. 51 (2016) 7-18.

31. N.Q. Chinh, T. Györi, R.Z. Valiev, P. Szommer, G. Varga, K. Havancsák, T.G. Langdon, Observations of unique plastic behavior in micro-pillars of an ultrafinegrained alloy, MRS Comm. 2 (2012) 75-78.

32. K. Yang, H.-J. Fecht, Y. Ivanisenko, First direct in situ observation of grain boundary sliding in ultrafine grained noble metal, Adv. Eng. Mater. 16 (2014) 517-521.

33. A.P. Zhilyaev, B.K. Kim, G.V. Nurislamova, M.D. Baró, J.A. Szpunar, T.G. Langdon, Orientation imaging microscopy of ultrafine-grained nickel, Scripta Mater. 46 (2002) 575-580.

34. A.P. Zhilyaev, G.V. Nurislamova, B.K. Kim, M.D. Baró, J.A. Szpunar, T.G. Langdon, Experimental parameters influencing grain refinement and microstructural evolution during highpressure torsion, Acta Mater. 51 (2003) 753-765.

35. J. Wongsa-Ngam, M. Kawasaki, T.G. Langdon, A comparison of microstructures and mechanical properties in a $\mathrm{Cu}-\mathrm{Zr}$ alloy processed using different SPD techniques, J. Mater. Sci. 48 (2013) 4653-4660.

36. K.-Y. Tsai, M.-H. Tsai, J.-W. Yeh, Sluggish diffusion in $\mathrm{Co}-\mathrm{Cr}-\mathrm{Fe}-\mathrm{Mn}-\mathrm{Ni}$ highentropy alloys, Acta Mater. 61 (2013) 4887-4897.

37. S.-Y. Chang, C.-E. Li, Y.-C. Huang, H.-F. Hsu, J.-W. Yeh, S.-J. Lin, Structural and thermodynamic factors of suppressed interdiffusion kinetics in multi-component high-entropy materials, Sci. Reports 4 (2014) 4162.

38. S.-Y. Chang, S.-Y. Lin, Y.-C. Huang, C.-L. Wu, Mechanical properties, deformation 
behaviors and interface adhesion of (AlCrTaTiZr) $\mathrm{N}_{\mathrm{x}}$ multi-component coatings, Surf. Coat. Tech. 204 (2010) 3307-3314.

39. I.-C. Choi, Y.-J. Kim, B. Ahn, M. Kawasaki, T.G. Langdon, J.-i. Jang, Evolution of plasticity, strain-rate sensitivity and the underlying deformation mechanism in Zn22\%Al during high-pressure torsion, Scripta Mater. 75 (2014) 102-105.

40. I.-C. Choi, D.-H. Lee, B. Ahn, K. Durst, M. Kawasaki, T.G. Langdon, J.-i. Jang, Enhancement of strain-rate sensitivity and shear yield strength of a magnesium alloy processed by high-pressure torsion, Scripta Mater. 94 (2015) 44-47.

41. B.N. Lucas, W.C. Oliver, Indentation power-law creep of high purity indium, Metall. Mater. Trans. A 30 (1999) 601-610.

42. R. Goodall, T.W. Clyne, A critical appraisal of the extraction of creep parameters from nanoindentation data obtained at room temperature, Acta Mater. 54 (2006) 5489-5499.

43. I.-C. Choi, B.-G. Yoo, Y.-J. Kim, M.-Y. Seok, Y.M. Wang, J.-i. Jang, Estimating the stress exponent of nanocrystalline nickel: Sharp vs. spherical indentation, Scripta Mater. 65 (2011) 300-303.

44. I.-C. Choi, B.-G. Yoo, J.-Y. Kim, J.-i. Jang, Indentation creep revisited, J. Mater. Res. 27 (2012) 3-11.

45. M. Kawasaki, T.G. Langdon, The significance of strain reversals during processing by high-pressure torsion, Mater. Sci. Eng. A 498 (2008) 341-348.

46. K.L. Johnson, Contact Mechanics, Cambridge University Press, Cambridge, 1985.

47. R.B. Figueiredo, P.R. Cetlin, T.G. Langdon, Using finite element modeling to examine the flow processes in quasiconstrained high-pressure torsion, Mater. Sci. Eng. A 528 (2011) 8198-8204.

48. Y. Wu, W.H. Liu, X.L. Wang, D. Ma, A.D. Stoica, T.G. Nieh, Z.B. He, Z.P. Lu, In-situ neutron diffraction study of deformation behavior of a multi-component high-entropy alloy, Appl. Phys. Lett. 104 (2014) 051910.

49. R.Z. Valiev, Y.V. Ivanisenko, E.F. Rauch, B. Baudelet, Structure and deformaton behaviour of Armco iron subjected to severe plastic deformation, Acta Mater. 44 (1996) 4705-4712.

50. G.A. Salishchev, M.A. Tikhonovsky, D.G. Shaysultanov, N.D. Stepanov, A.V. Kuznetsov, I.V. Kolodiy, A.S. Tortika, O.N. Senkov, Effect of Mn and V on structure and mechanical properties of high-entropy alloys based on $\mathrm{CoCrFeNi}$ system, J. Alloys Compd. 591 (2014) 11-21.

51. C. Zhu, Z.P. Lu, T.G. Nieh, Incipient plasticity and dislocation nucleation of FeCoCrNiMn high-entropy alloy, Acta Mater. 61 (2013) 2993-3001.

52. B.-G. Yoo, K.-S. Kim, J.-H. Oh, U. Ramamurty, J.-i. Jang, Room temperature creep in amorphous alloys: Influence of initial strain and free volume, Scripta Mater. 63 (2010) 1205-1208.

53. Y.-J. Kim, I.-C. Choi, J.-A Lee, M.-Y. Seok, J.-i. Jang, Strain-dependent transition of time-dependent deformation mechanism in single crystal $\mathrm{ZnO}$ evaluated by spherical nanoindentation, Philos. Mag. 95 (2015) 1896-1906.

54. C.L. Wang, Y.H. Lai, J.C. Huang, T.G. Nieh, Creep of nanocrystalline nickel: A direct comparison between uniaxial and nanoindentation creep, Scripta Mater. 62 (2010) 17178.

55. P. Yavari, T.G. Langdon, An examination of the breakdown in creep by viscous glide in solid solution alloys at high stress levels, Acta Metall. 30 (1982) 2181-2196.

56. T.G. Langdon, Grain boundary sliding revisited: Developments in sliding over four decades, J. Mater. Sci. 41 (2006) 597-609.

57. I.-C. Choi, Y.-J. Kim, M.-Y. Seok, B.-G. Yoo, J.-Y. Kim, Y.M. Wang, J.-i. Jang, 
Nanoscale room temperature creep of nanocrystalline nickel pillars at low stresses, Int. J. Plasticity 41 (2013) 53-64.

58. T. Zhu, J. Li, A. Samanta, H.-G. Kim, S. Suresh, Interfacial plasticity governs strain rate sensitivity and ductility in nanostructured metals, Proc. Natl. Acad. Sci. USA 104 (2007) 3031-3036.

59. H. Conrad, Grain size dependence of the plastic deformation kinetics in $\mathrm{Cu}$, Mater. Sci. Eng. A 341 (2003) 216-228.

60. H. Conrad, Plastic deformation kinetics in nanocrystalline fcc metals based on the pile-up of dislocations, Nanotechnology 18 (2007) 325701.

61. H.J. Frost, M.F. Ashby: Deformation-mechanism maps (Pergamon Press, Oxford, 1982).

62. F. Wang, P. Huang, T. Lu, Surface-effect territory in small volume creep deformation, J. Mater. Res. 24 (2009) 3277-3285.

63. C.A. Schuh, J.K. Mason, A.C. Lund, Quantitative insight into dislocation nucleation from high-temperature nanoindentation experiments, Nat. Mater. 4 (2005) 617-621.

64. R.L. Coble, A model for boundary diffusion controlled creep in polycrystalline materials, J. Appl. Phys. 34 (1963) 1679-1682.

65. Z. Horita, D.J. Smith, M. Furukawa, M. Nemoto, R.Z. Valiev, T.G. Langdon, An investigation of grain boundaries in submicrometer-grained $\mathrm{Al}-\mathrm{Mg}$ solid solution alloys using high-resolution electron microscopy, J. Mater Res. 11 (1996) 1880-1890.

66. A.M. Brown, M.F. Ashby, Correlations for diffusion constants, Acta Metall. 28 (1980) 1085-1101.

67. J.D. Eshelby, The continuum theory of lattice defects, in: S. Frederick, T. David (Eds.), Solid State Physics, Academic Press, 1956, pp. 79-144.

68. Y.F. Ye, C.T. Liu, Y. Yang, A geometric model for intrinsic residual strain and phase stability in high entropy alloys, Acta Mater. 94 (2015) 152-161.

69. http://periodictable.com/Properties/A/BulkModulus.html.

70. A. Takeuchi, A. Inoue, Mixing enthalpy of liquid phase calculated by miedema's scheme and approximated with sub-regular solution model for assessing forming ability of amorphous and glassy alloys, Intermetallics 18 (2010) 1779-1789.

71. J.Y. He, C. Zhu, D.Q. Zhou, W.H. Liu, T.G. Nieh, Z.P. Lu, Steady state flow of the FeCoNiCrMn high entropy alloy at elevated temperatures, Intermetallics, 55 (2014) 9-14.

72. W.H. Poisl, W.C. Oliver, B.D. Fabes, The relationship between indentation and uniaxial creep in amorphous selenium, J. Mater. Res. 10 (1995) 2024-2032.

73. V. Maier, K. Durst, J. Mueller, B. Backers, H.W. Höppel, M. Göken, Nanoindentation strain-rate jump tests for determining the local strain-rate sensitivity in nanocrystalline Ni and ultrafine-grained Al, J. Mater. Res. 26 (2011) 1421-1430.

74. T.G. Langdon, A method of distinguishing between diffusion creep and Harper-Dorn creep at low stress levels, Scipta Mater. 35 (1996) 733-737.

75. Z.S. Ma, S.G. Long, Y. Pan, Y.C. Zhou, Loading rate sensitivity of nanoindentation creep in polycrystalline Ni films, J. Mater. Sci. 43 (2008) 5952-5955.

76. Z.S. Ma, S.G. Long, Y.C. Zhou, Y. Pan, Indentation scale dependence of tip-in creep behavior in Ni thin films, Scripta Mater. 59 (2008) 195-198.

77. Z. Wang, S. Guo, Q. Wang, Z. Liu, J. Wang, Y. Yang, C.T. Liu, Nanoindentation characterized initial creep behavior of a high-entropy-based alloy CoFeNi, Intermetallics, 53 (2014) 183-186.

78. H. Li, A.H.W. Ngan, Size effects of nanoindentation creep, J. Mater. Res. 19 (2004) 513-522.

79. W.C. Oliver, G.M. Pharr, An improved technique for determining hardness and elastic 
modulus using load and displacement sensing indentation experiments, J. Mater. Res. 7 (1992) 1564-1583.

80. W.C. Oliver, G.M. Pharr, Measurement of hardness and elastic modulus by instrumented indentation: Advances in understanding and refinements to methodology, J. Mater. Res. 19 (2004) 3-20.

81. T.G. Langdon, Creep at low stresses: an evaluation of diffusion creep and HarperDorn creep as viable creep mechanisms, Metall. Mater. Trans. 33 A (2002) 249-259. 


\section{$\underline{\text { List of Tables and Figures }}$}

Table 1 Bulk modulus $(K)$ and atomic volume $(\Omega)$ for each constituent element in CoCrFeMnNi system [69].

Table 2 The mixing enthalpy of binary equiatomic alloys $\left(\Delta H_{i j}{ }^{\mathrm{mix}}\right)$ calculated by Miedema's approach [70].

Fig. 1 Variations in hardness as a function of applied equivalent strain. The inset illustrates the distribution of equivalent strain over the one-quarter disk after $\sim 1 / 4$ turn. The locations of hardness indentation are represented as cross mark.

Fig. 2. Microstructural evolution during HPT; (a) optical micrograph and (b) EBSD image of as-cast sample; (c) BF TEM images and SAD patterns (inset) taken at the edges of the HPT disks after 1/4 and (d) 2 turns.

Fig. 3 Representative $P$ - $h$ curves recorded during quasi-static nanoindentation tests with a spherical indenter.

Fig. 4 Typical examples of $P$ - $h$ curves obtained during spherical indentation creep tests; (a) elastic regime and (b) elastic-plastic regime.

Fig. 5 Total creep displacement vs. peak load plots for nc and cg HEAs.

Fig. 6 Typical examples of strain rate vs. holding time (with the inset showing creep strain vs. holding time); (a) nc HEA for $d \sim 33 \mathrm{~nm}$ and (b) $49 \mathrm{~nm}$; (c) cg HEA.

Fig. 7 Relations between QSS creep strain rate and stress, of which slope corresponds to the creep stress exponent $n$.

Fig. 8 Logarithmic strain rate vs. linear stress relation to estimate the activation volume $V^{*}$ for creep. 
Fig. 9 Representative examples of $\log -\log$ plots of strain rate vs. stress obtained from Berkovich indentation creep experiments at different $P_{\max }$. 
Table 1

\begin{tabular}{c|c|c|c|c|c}
\hline \hline & Co & Cr & Fe & Mn & Ni \\
\hline \hline $\boldsymbol{K}[\mathbf{G P a}]$ & 180 & 160 & 170 & 120 & 180 \\
\hline $\boldsymbol{\Omega}\left[\AA^{3}\right]$ & 14.7 & 19.2 & 15.9 & 17.5 & 13.9 \\
\hline
\end{tabular}


Table 2

\begin{tabular}{c|c|c|c|c|c}
\hline \hline & Co & Cr & Fe & Mn & Ni \\
\hline \hline $\mathbf{C o}$ & 0 & -4.5 & -0.6 & -5.2 & -0.2 \\
\hline $\mathbf{C r}$ & -4.5 & 0 & -1.5 & 2.1 & -6.7 \\
\hline $\mathbf{F e}$ & -0.6 & -1.5 & 0 & 0.2 & -1.6 \\
\hline $\mathbf{M n}$ & -5.2 & 2.1 & 0.2 & 0 & -8.2 \\
\hline $\mathbf{N i}$ & -0.2 & -6.7 & -1.6 & -8.2 & 0 \\
\hline
\end{tabular}




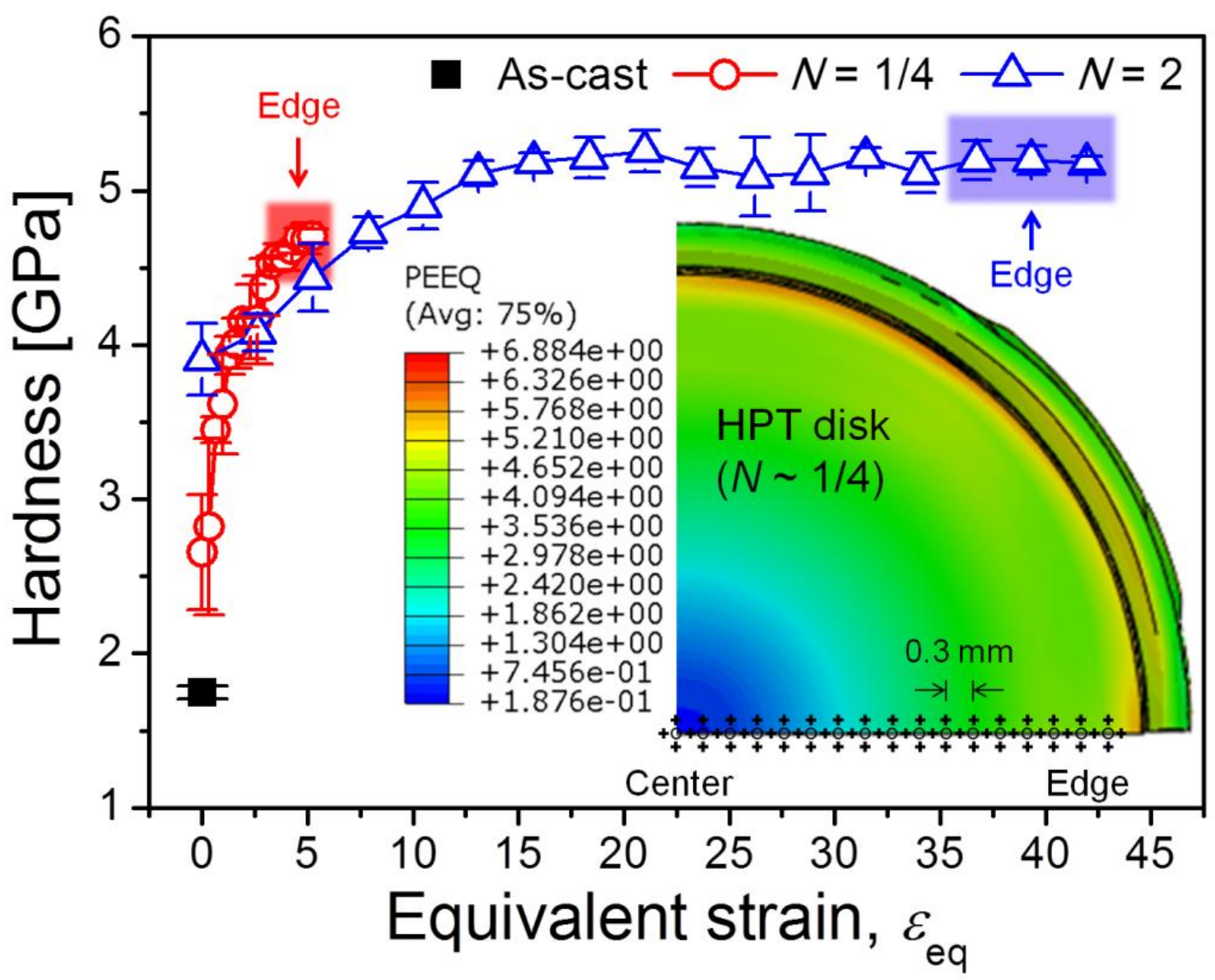

Fig.1 


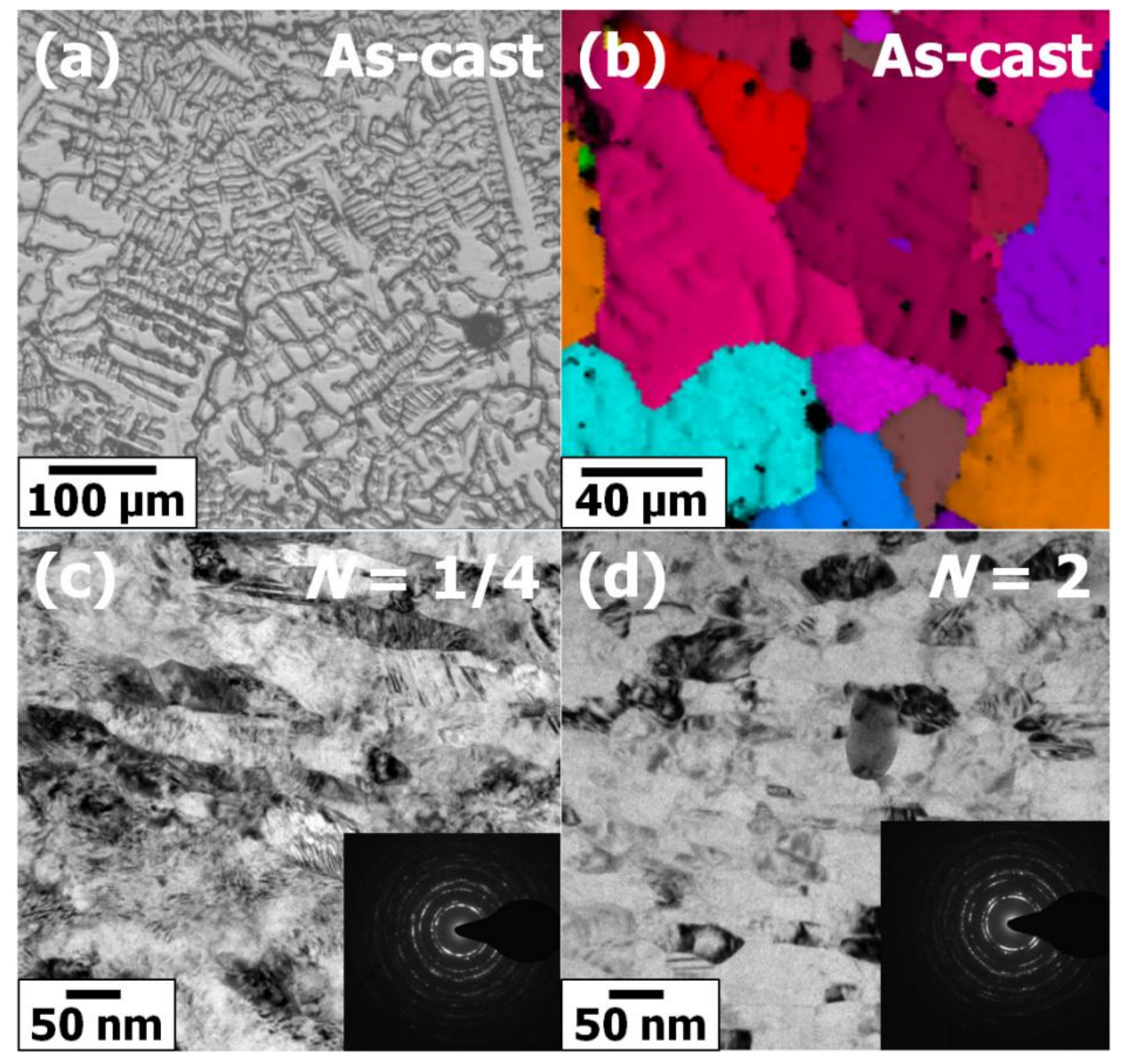

Fig. 2 


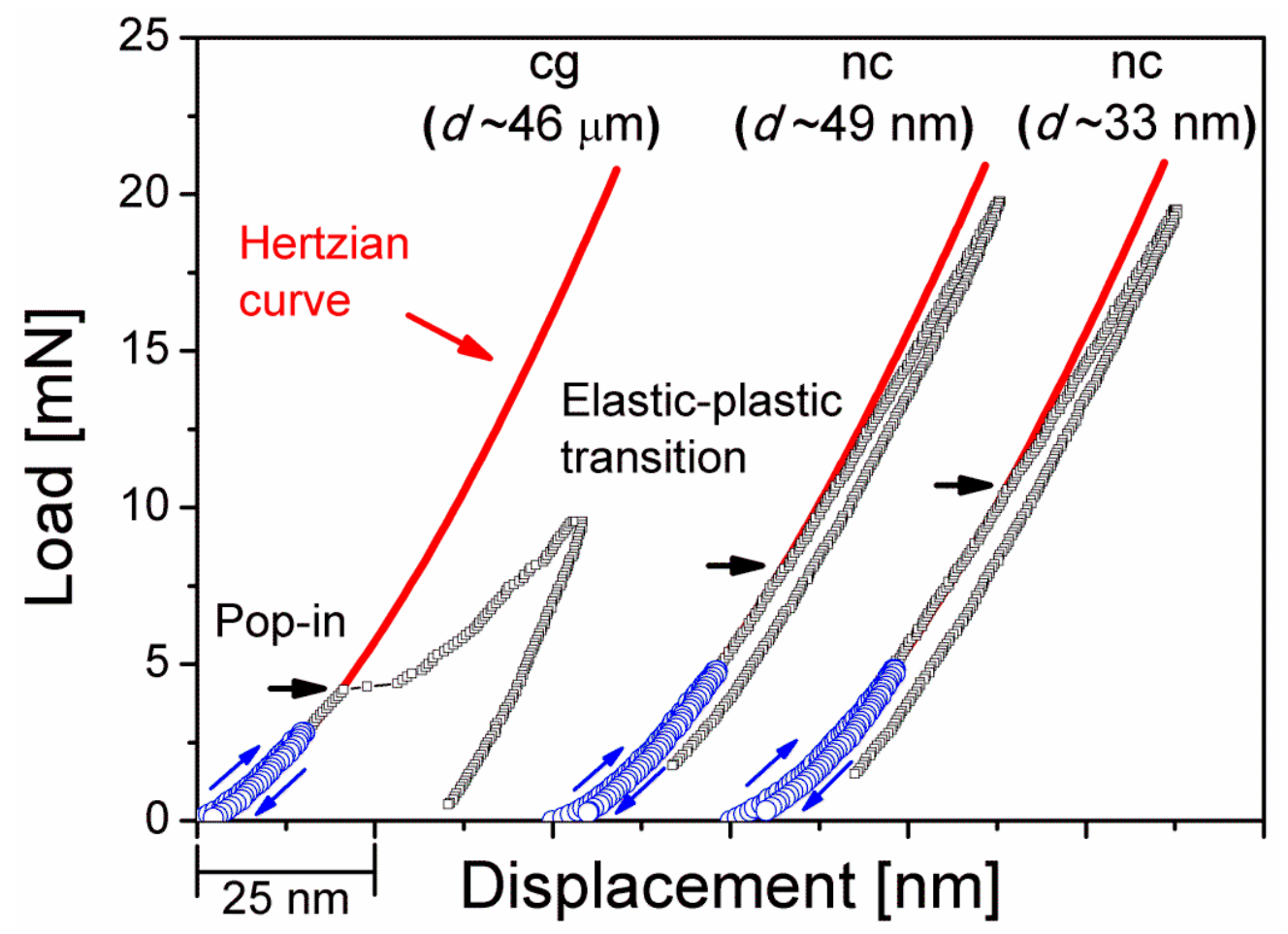

Fig. 3 


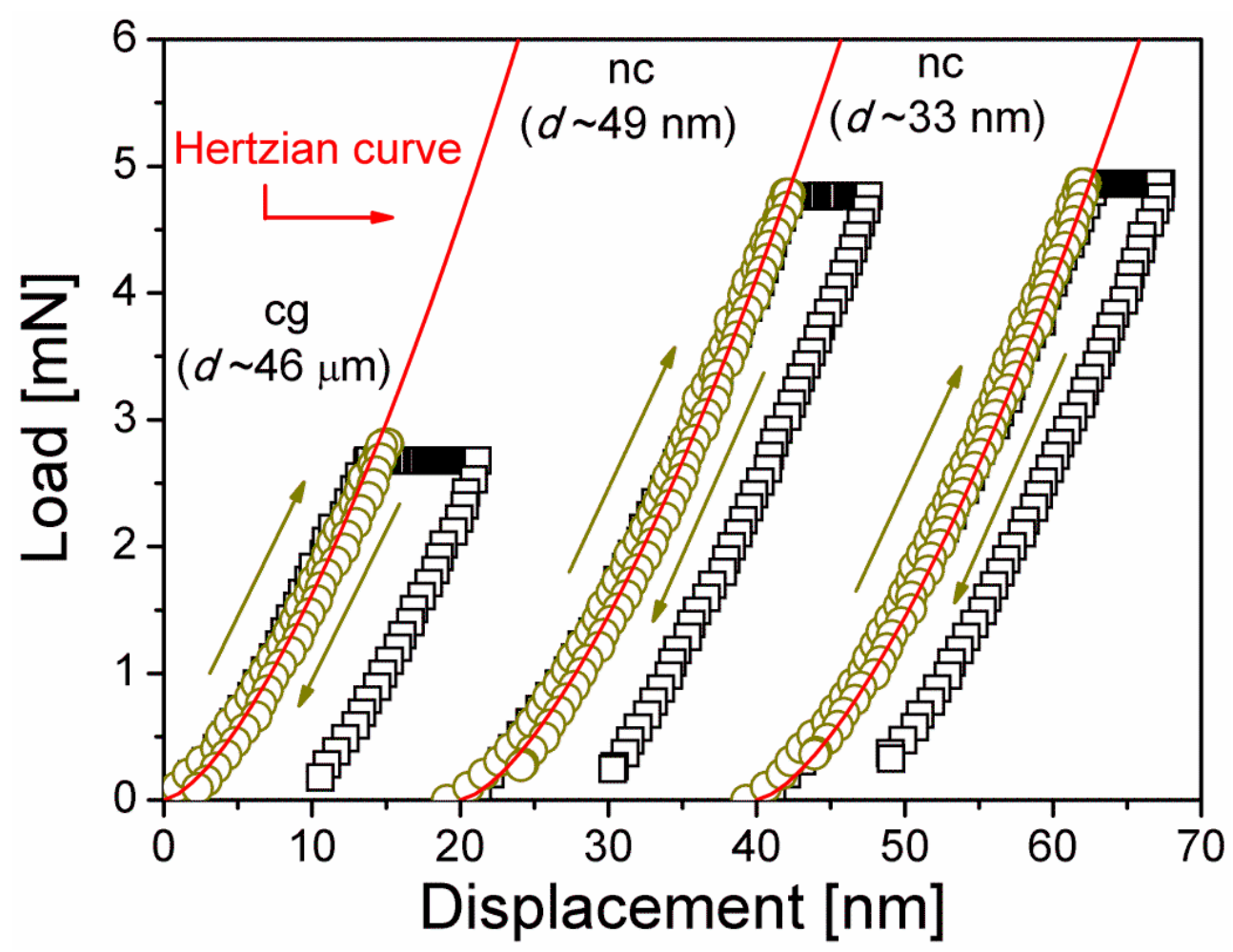

(a)

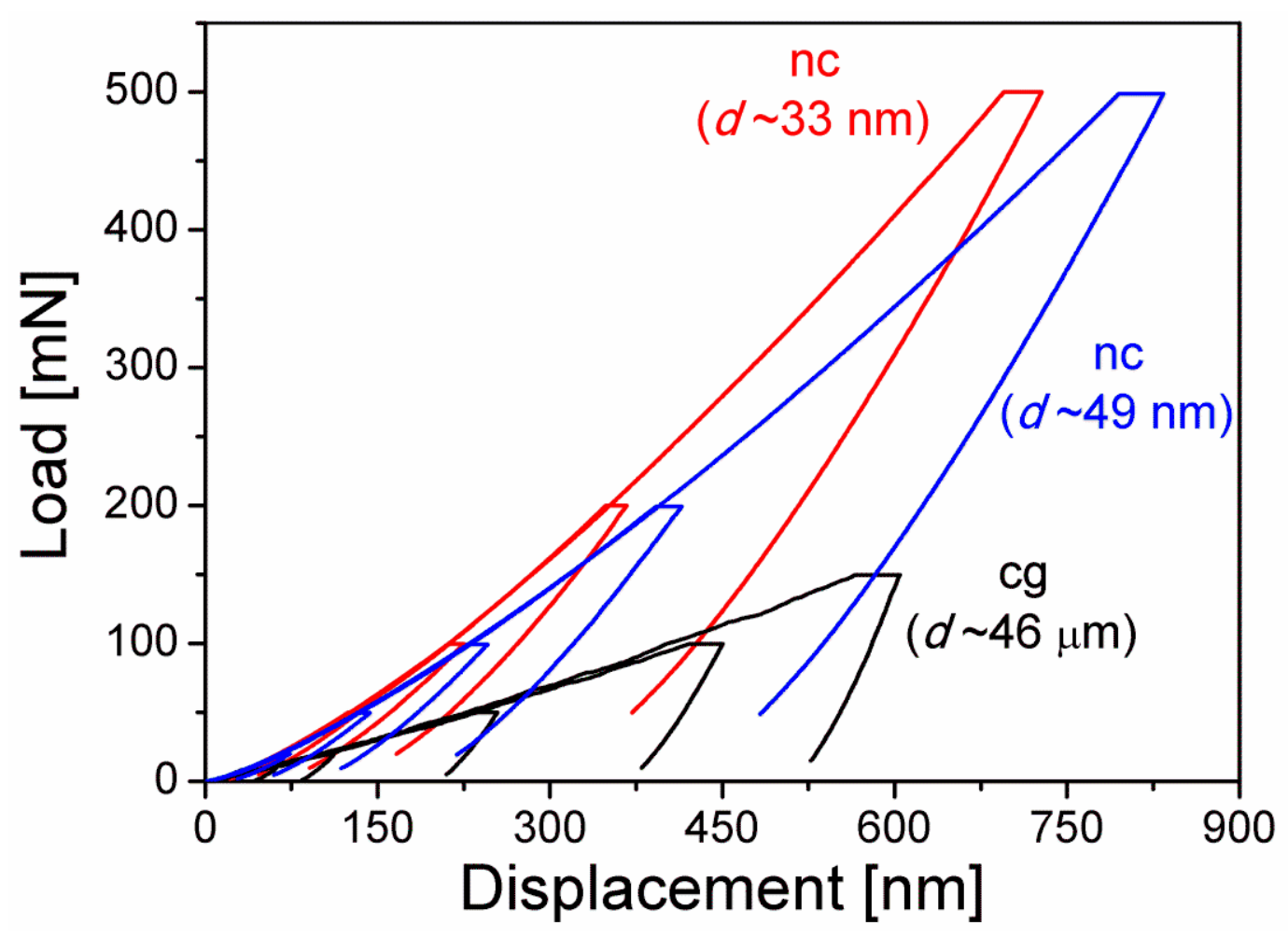

(b)

Fig. 4 


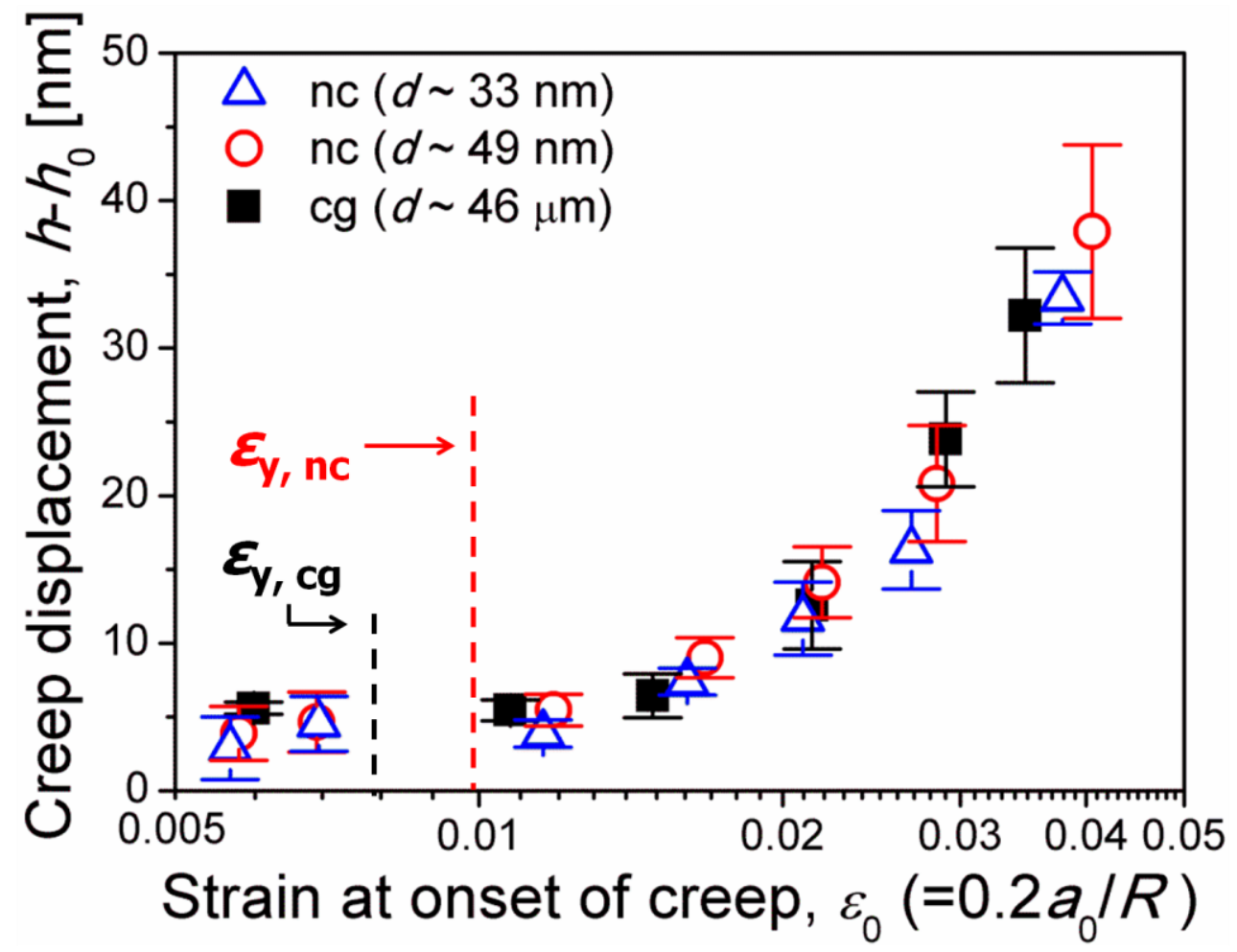

Fig. 5 


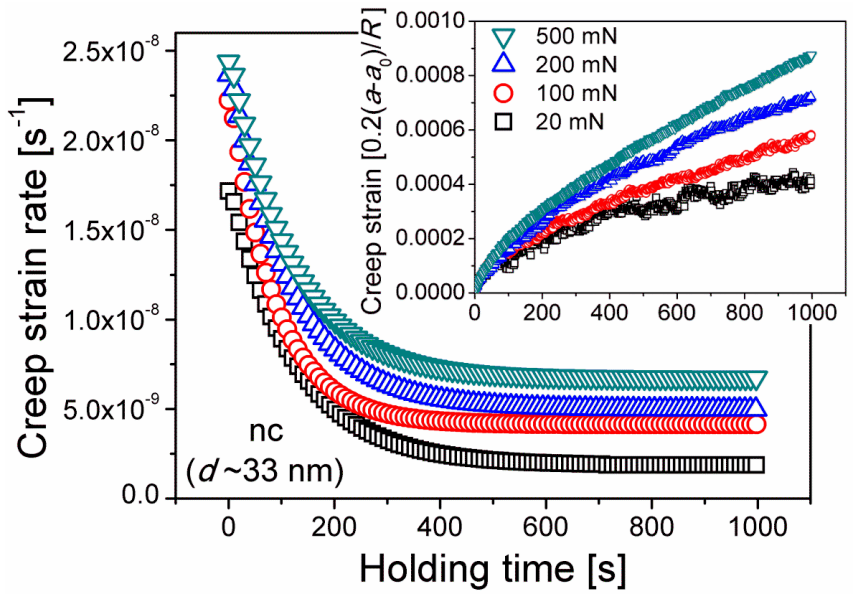

(a)

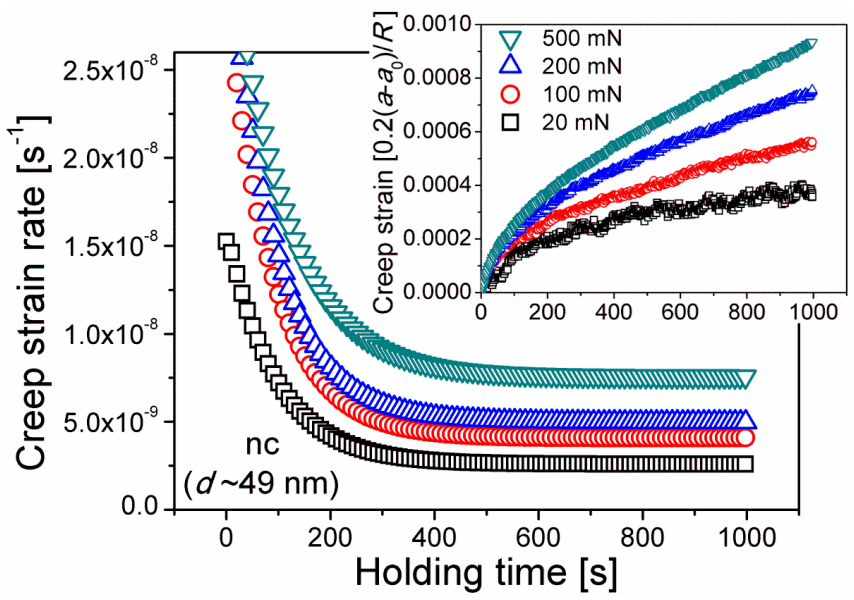

(b)

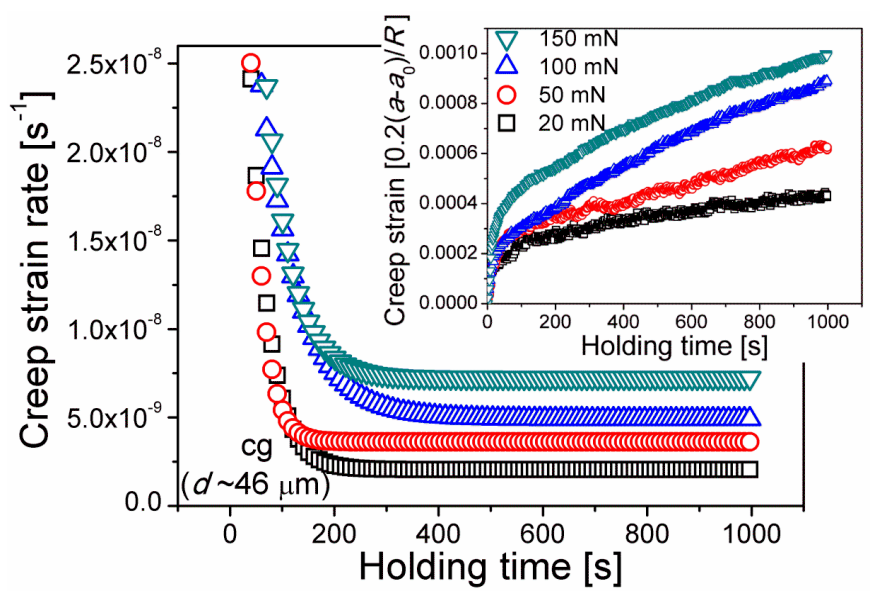

(c)

Fig. 6 


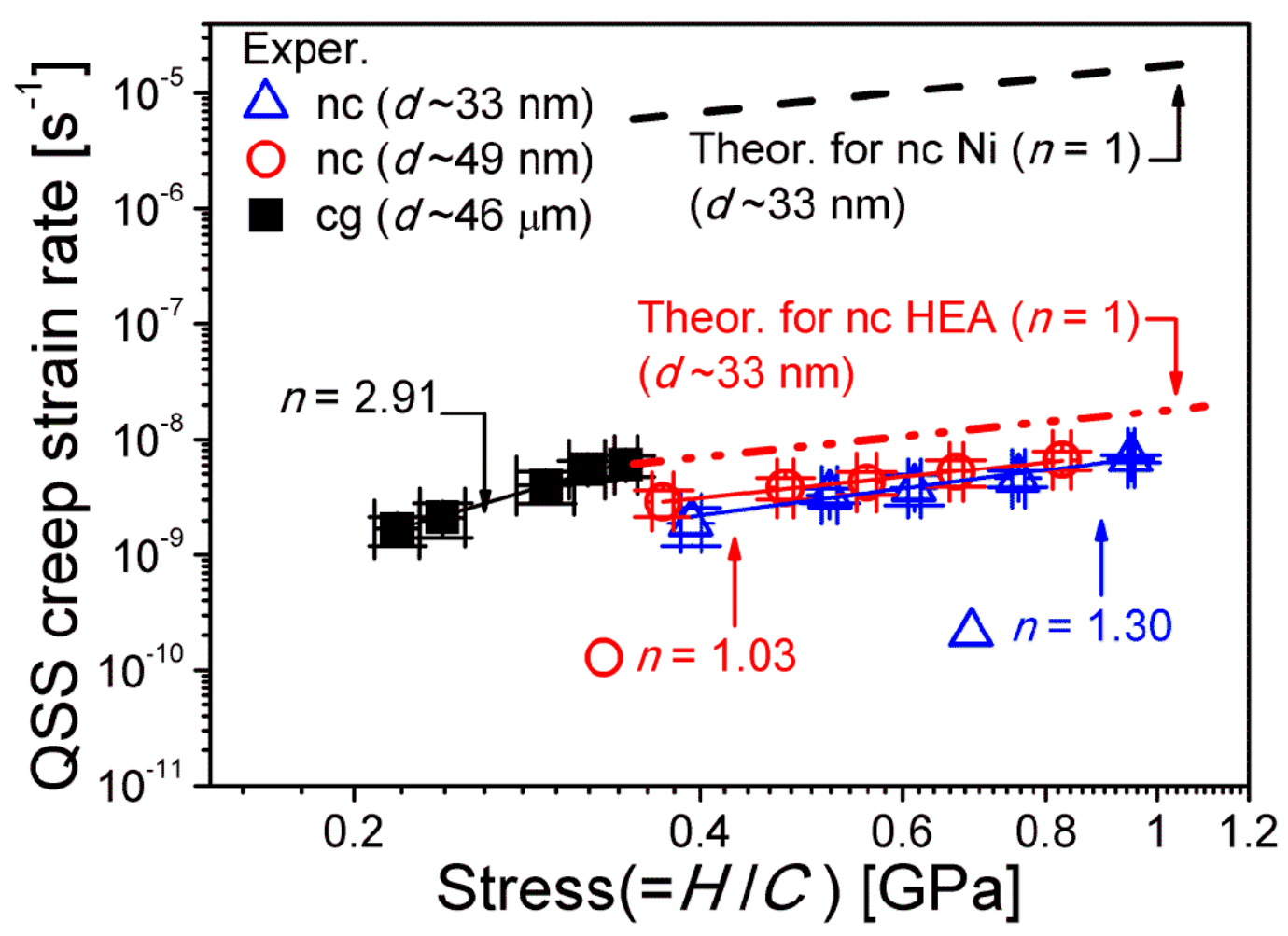

Fig. 7 


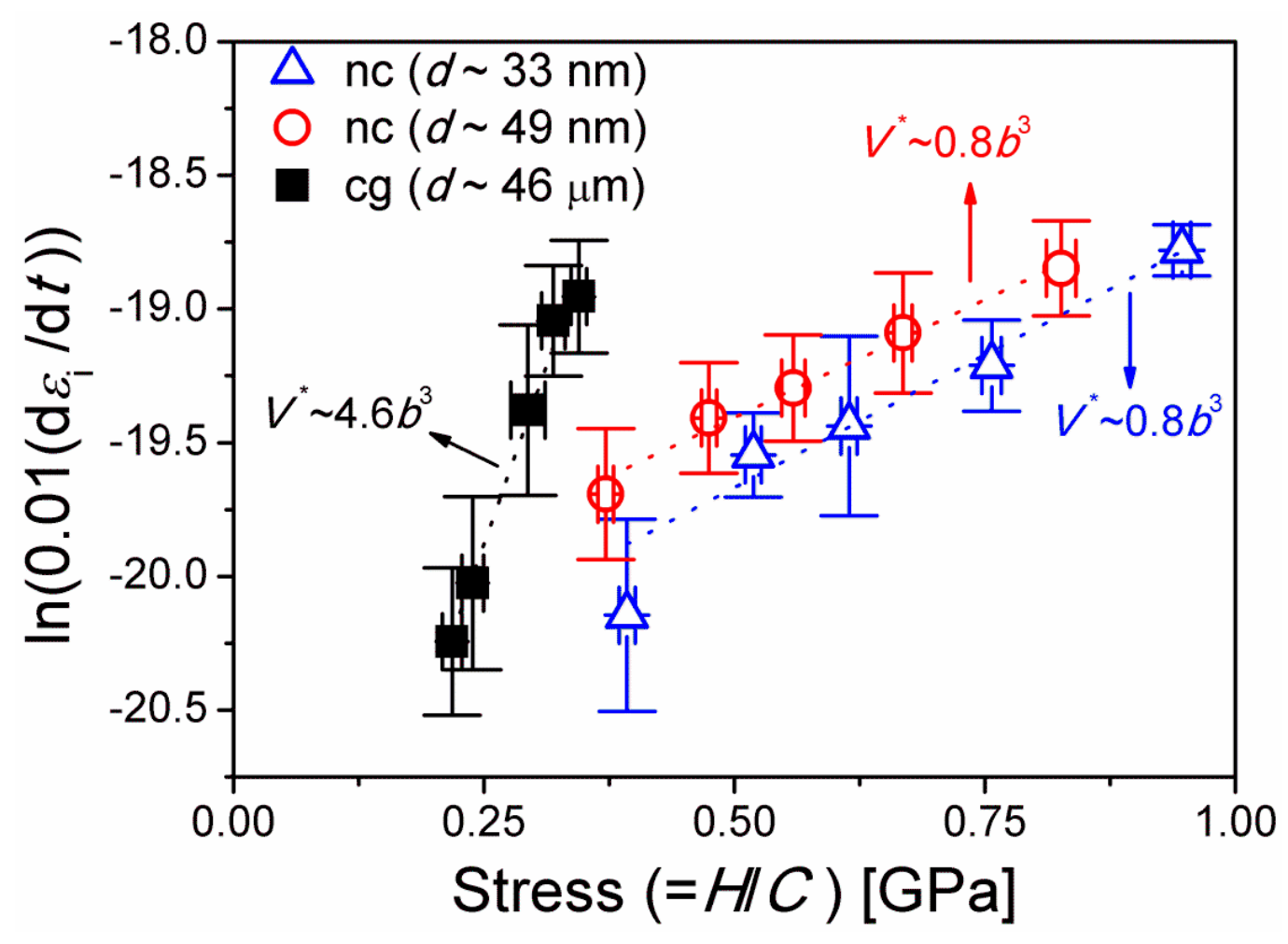

Fig. 8 


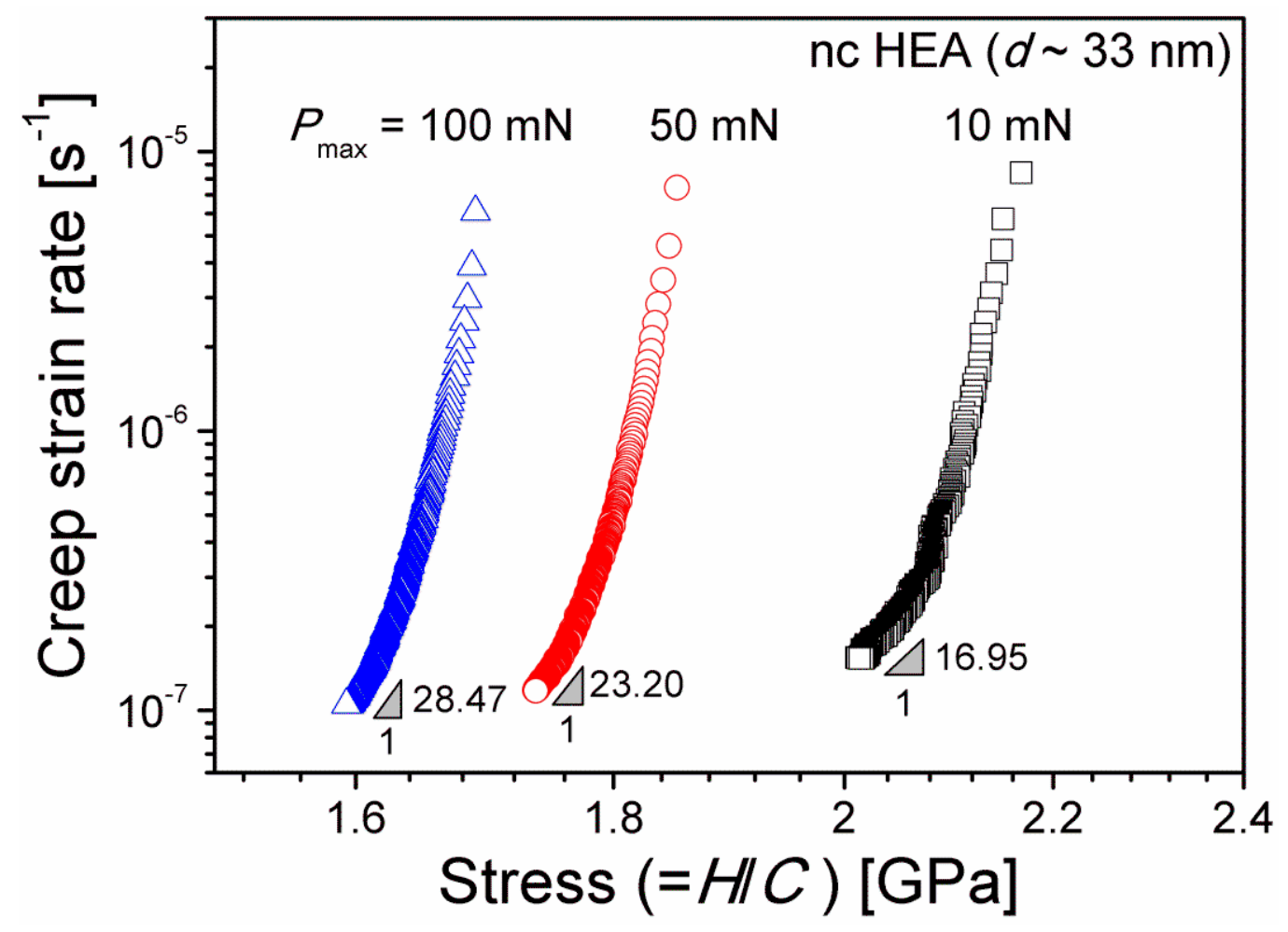

Fig. 9 

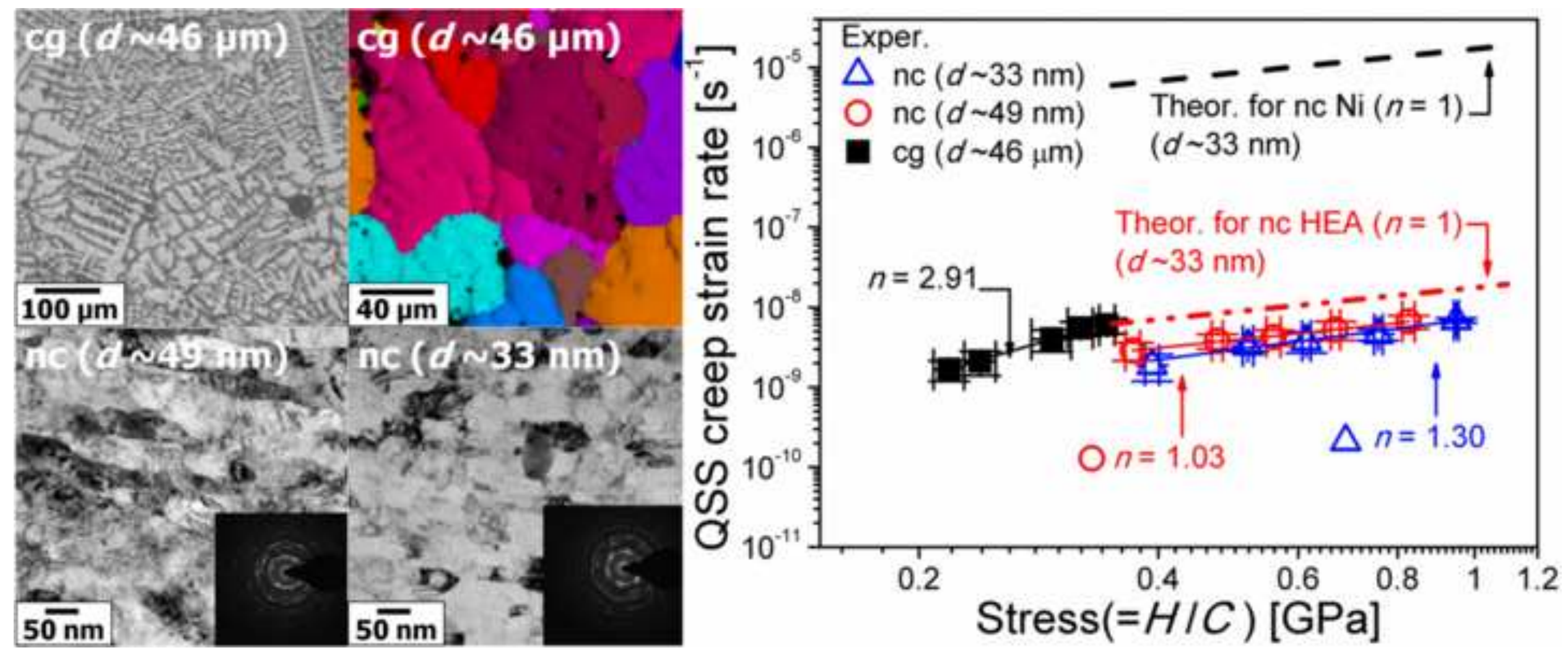